\title{
Assessing the required life-cycle characteristics of electricity storage for ensuring sustainability in buildings
}

\section{Didier Vuarnoz}

To cite this article: Didier Vuarnoz (2020): Assessing the required life-cycle characteristics of electricity storage for ensuring sustainability in buildings, Architectural Science Review

To link to this article: https://doi.org/10.1080/00038628.2020.1772193

册 Published online: 02 Jun 2020.

Submit your article to this journal $₫$

Q View related articles $₫$

View Crossmark data \lceil 


\title{
Assessing the required life-cycle characteristics of electricity storage for ensuring sustainability in buildings
}

\author{
Didier Vuarnoz ${ }^{\mathrm{a}, \mathrm{b}}$ \\ ${ }^{\mathrm{a}}$ Energy Institute, University of Applied Sciences of Western Switzerland, Fribourg, Switzerland; ${ }^{\mathrm{b}}$ Building 2050 Research Group, Ecole Polytechnique \\ Fédérale de Lausanne (EPFL), Fribourg, Switzerland
}

\begin{abstract}
In high-performance buildings, energy storage is a key component in increasing self-consumption of onsite renewable energy, but is also responsible for extra embedded burdens. The main risk is not paying back these extra burdens through operational benefits during the use phase of the building. The aim of this study is to define, explore and propose a methodology for assessing the limits of the viability of energy storage systems when embedded in a building, utilising a set of indicators including greenhouse gas emissions, primary energy and costs. These values are therefore of importance when designing a building energy system integrating renewable energy source and energy storage. Beyond the results obtained for a case study in Switzerland, the study unveils different mechanisms according to the scheme of renewable energy exports. Results are greatly affected by the geographic context and demonstrate the necessity to implement harvesting systems providing low-impact renewable energy in buildings.
\end{abstract}

ARTICLE HISTORY

Received 30 April 2020

Accepted 18 May 2020

\section{KEYWORDS}

High-performance building; energy storage; viability; GHG emissions; primary energy; levelized cost of operational energy

\section{Nomenclature}

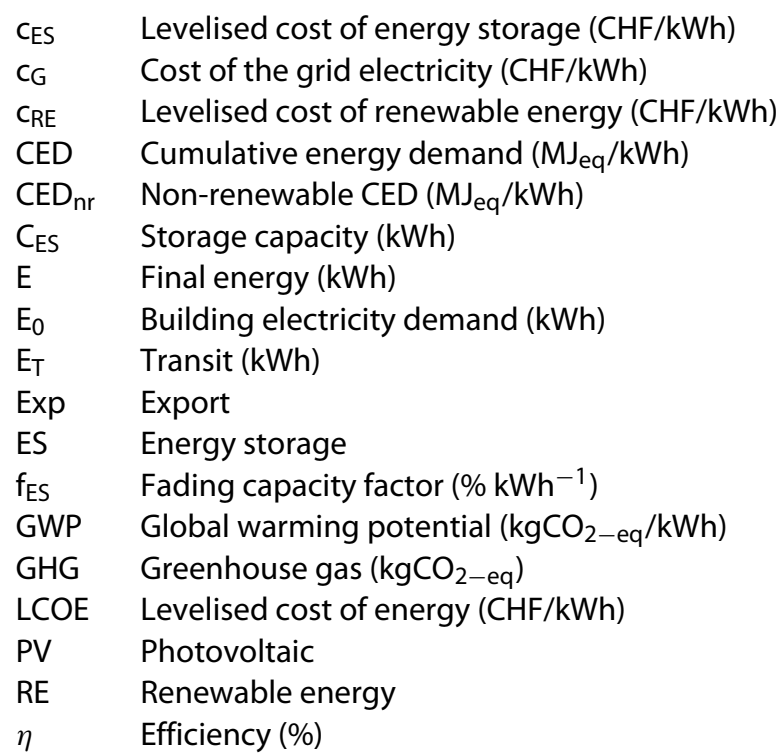

\section{Introduction}

High-performance buildings require very low energy demand supplied mostly from renewable sources, implying a strong transdisciplinary approach between architecture and engineering. A main problem with intermittent renewable energy (RE) sources (e.g. wind, solar) is the temporal mismatch between their availability and the demand for energy. In buildings, energy storage (ES) coupled with photovoltaic (PV) systems represent a promising solution to increase self-consumption of on-site
RE (Velik 2013; Litjens, Worrell, and van Sark 2018; Vieira, Moura, and de Almeida 2017). The design of energy storage systems involves selecting the technology, defining an appropriate storage capacity and selecting an appropriate energy management strategy (EMS).

As storage capacity affects self-consumption (Velik 2013), environmental impacts (Celik, Muneer, and Clarke 2007; McManus 2015) and costs (Celik et al., 2007), the optimal sizing of storage capacity is a growing focus of numerous recent research papers and focus mainly in limiting and using the amount of storage capacity efficiently is a priority. Optimal design is investigated for maximizing different cost indicators, such as the 'home economy' (Wu et al. 2017), the net present value (Zhang et al. 2017). In Doroudchi et al. (2015), the optimal capacity is considered to be the smallest necessary, thereby enabling the minimization of operational costs with a scoring function. By assessing the probability of exceeding the maximum storage availability, Guarino and colleagues (2015) investigated the best trade-off between storage size and system efficiency. The existing literature does not provide an ultimate method for the storage capacity, especially because this capacity is usually determined on the basis of the transient operations of the BES, and therefore, by the EMS.

Among the possible EMS, the most common is referred to as the 'traditional' strategy and prioritizes the self-consumption of on-site RE (see e.g. Zhang et al. 2017; Vuarnoz et al. 2018). The minimization of cost is achieved by different computational approaches, for example, convex programming (Wu et al. 2017), mixed-integer linear programming (Doroudchi et al. 2015), and adaptative dynamic programming (Huang and Liu 2011). Zhang and colleagues (2017) found that the dynamic price load shifting 
strategy has a similar performance than the conventional operational strategy when electricity price variation is not large enough. Vuarnoz et al. (2018) tested other single objective optimizations; they also demonstrated performances similar to those obtained with a traditional EMS when optimization concerns primary energy. When optimization is made for GHG emissions, the very limited gains are obtained at the detriment of the primary energy (Vuarnoz et al. 2018). A combination of operation strategies was identified by Zhang et al. (2017), and the results obtained outperformed other single optimization strategies (traditional and dynamic price load shifting). Hoan-Anh and co-workers coupled the solar forecast with energy prices (Hoan-Anh, Delinchant, and Wurtz 2013) and Favre et al. (2018) demonstrated the possibility of optimizing at the same time operational cost, self-consumption and GHG emissions with the use of a genetic algorithm. It is foreseeable that other types of EMS dedicated to BES will emerge in the future.

Although the search for different optimums for determining the storage capacity, as well as the best operating conditions, is the scope of many articles found in the literature, these optimums do not necessarily lead to life-cycle viability of deploying energy storage in the construction sector. One of the most used key performance indicators for assessing highperformance buildings is the Net Zero Energy Building balance, which allows the energy balance analysis at the building level, but does not allow for assessing and confirming the benefits of implementing ES in buildings. ES increases the burdens associated with stored energy and not only because of operational efficiency. The reason lies in the extra elements added to the building energy system (BES), each one with its own embodied environmental impacts, grey energy, and investment costs. For each life-cycle indicator characterising ES (see e.g. Kourkoumpas et al. 2018), there is a trade-off between the operational benefit and the extra embedded impact (Vuarnoz and Jusselme 2018b), which is seldom investigated specifically for energy storage in buildings.

Responding to this gap in knowledge, this study focuses on general methodology for assessing the cut-off value at which the operational benefits enabled by an energy storage unit in a building exactly balance its extra embedded impact. This is particularly relevant to ensure the cradle-to-grave life-cycle sustainability of an energy storage system, whatever storage capacity sizing technique and EMS is used. The methodology is independent of the choice of storage technology, and therefore, this aspect is not addressed in the present study. Interested readers may find a helpful overview of the technology characteristics of different kinds of storage in Barnhart and Benson (2013) or in Kourkoumpas et al. (2018), for example.

The proposed method is applicable for any kind of lifecycle indicators, but due to the present crisis of global warming and the urgent need of the building sector to constrict its carbon footprint, we found it appropriate to explain the proposed methodology for the GHG emissions. The primary energy and cost indicators are also derived in the present article. The expected audience of this study is composed of LCA practitioners and energy engineers and researchers, but also building planners and architects.

The remainder of the paper is arranged as follows. Section 2 presents the life-cycle framework and principles used for the analysis. The methodology for assessing the limits of the viability of an energy storage unit in a given building is unveiled in Section 3. The application of the methodology to a specific case study is formulated in Section 4. In Section 5, the obtained results are discussed specifically for the case study and beyond the context of the case study. Conclusions are summarized in Section 6.

\section{Life-cycle approach}

\subsection{Selected indicators and functional units}

Three life-cycle indicators are used in the present study and specifically concern the GHG emissions, the primary energy and the costs. These indicators are assessed along their entire life cycles on a cradle-to-grave framework (extraction of resources, manufacturing, use, and final disposal of products and byproducts).

When considering GHG emissions, the quantity is hereafter called global warming potential (GWP), but also known as the carbon footprint of electricity (Kopsakangas-Savolainen et al., 2017 ), $\mathrm{CO}_{2-\text { eq }}$ footprint (Roux, Schalbart, and Peuportier 2016), conversion factor for GHG emissions (Vuarnoz and Jusselme 2018a), or emission factor (Milovanoff 2016), and it is expressed in $\mathrm{kg} \mathrm{CO} 2$-eq per $\mathrm{kWh}$ of electricity (final energy).

The energy use associated with the functional unit of 1 kWh of electricity is usually called primary energy (see e.g. SIA 2040 2017) and is also sometimes referred to as cumulative energy demand (CED). It is customary to differentiate CED from the renewable and non-renewable contributions, and both are expressed in $\mathrm{MJ}_{- \text {eq }}$ per kWh of electricity (final energy).

Concerning cost, the life-cycle approach is replaced with a levelized cost of energy that uses the same starting and ending boundaries (cradle-to-grave). The main difference is the price paid by the consumer at market delivery, which comprises production costs (cradle-to-gate) plus a margin from the manufacturer. As for PV, the end-of-life cost of batteries is financed in Switzerland by an anticipated recycling tax taken into consideration in the purchase of the system (SENS eRecycling 2019).

For the sake of simplicity, the further sections of this article will be limited to the description of the GWP indicators. The method is extended by analogy to primary energy and costs in Section 3.2.

\subsection{The different electricity sources}

A grid-connected building mounted with both photovoltaic and energy storage capabilities can enable its different building services through electricity. Preferably, this electricity comes directly from the solar panels, then from the battery and finally from the surrounding grid mix.

For PV-based electricity, we assess GWP as the ratio of the cradle-to-grave embedded GHG emissions of the PV system (Andersen and Rey 2019) over its predictable energy generation during its entire lifespan. The value of GWPPV is timeindependent when $E_{P V}$ is available, i.e. during the duration of sunshine (see Figure 1).

The carbon footprint of the electricity delivered by an ES system consists of the initial footprint of the electricity feeding its 

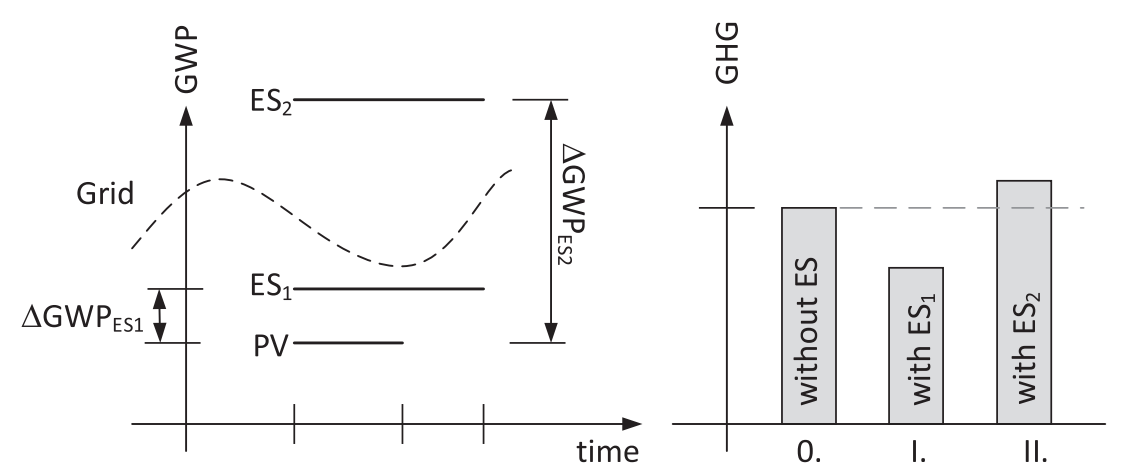

Figure 1. The GWP of the different sources of electricity supply (Left) combined with operational benefits of an energy storage govern the mechanism of the lifecycle GHG emission at the building level (Right).

inlet (usually provided by PV) and the footprint of the storage itself $\left(G W P_{E S}\right)$ (see Figure 1). The assessment of $G W P_{E S}$ is performed on the basis of an inventory of the material resources and the total energy processed during the storage system's lifespan.

In a national electricity grid, the share of each electricitygeneration technology (e.g. coal, hydro, etc.) varies continually over time according to each fuel's characteristics (availability and possibility of modulating power production) in order to adapt supply to the ever-changing demand. The same applies to the domestic export and import of electricity. Therefore, each $\mathrm{kWh}$ at the consumer's disposal does not have the same footprint over time (the case of the GWP indicator is presented in Figure 1, left side). Despite this situation, it is still common to use a yearly averaged $G W P_{G}$ when considering an electricity mix for performing GHG emissions assessments. This standard practice could soon be revised due to the potentially large inaccuracies of carbon emission assessments (Milovanoff 2016; Spork et al. 2015; Frischknecht et al. 2015) and the late emergence of hourly GWP assessments for different countries (see e.g. Milovanoff 2016; Vuarnoz et al.2016; Tomorrow 2018). In the present study, hourly GWP values of a grid mix are considered.

\subsection{GHG emissions mechanism}

To illustrate the GHG mechanism in which the operational benefit of using ES is combined with its own embedded impact, let us consider a baseline consisting of a building with an energy system that include on-site RE production, but that does not include energy storage. The resulting GHG emissions at the building level are taken as a baseline (Case 0 in the right part of Figure 1).

Then, we consider the implementation of $E S$, which has a low GWP (GWP $P_{\mathrm{ES} 1}$ ) that can easily be balanced by operational gain. Accordingly, the GHG emissions of the system are lower than the one considered in the initial case (as seen in case I in the right part of Figure 1). A second case (case II in Figure 1) is considered to illustrate the GHG mechanisms and depicts another storage system with a much higher GWP than case I (GWP $\mathrm{ESS}_{2}$ ). This is the case for example when a large storage capacity is available but seldom used. As a consequence, associated GHG emissions assessed at the building level would be so high that they could not be balanced during the lifespan of the energy storage system. As such, there is a threshold value where GHG emissions benefit by using ES at the outset to compensate for

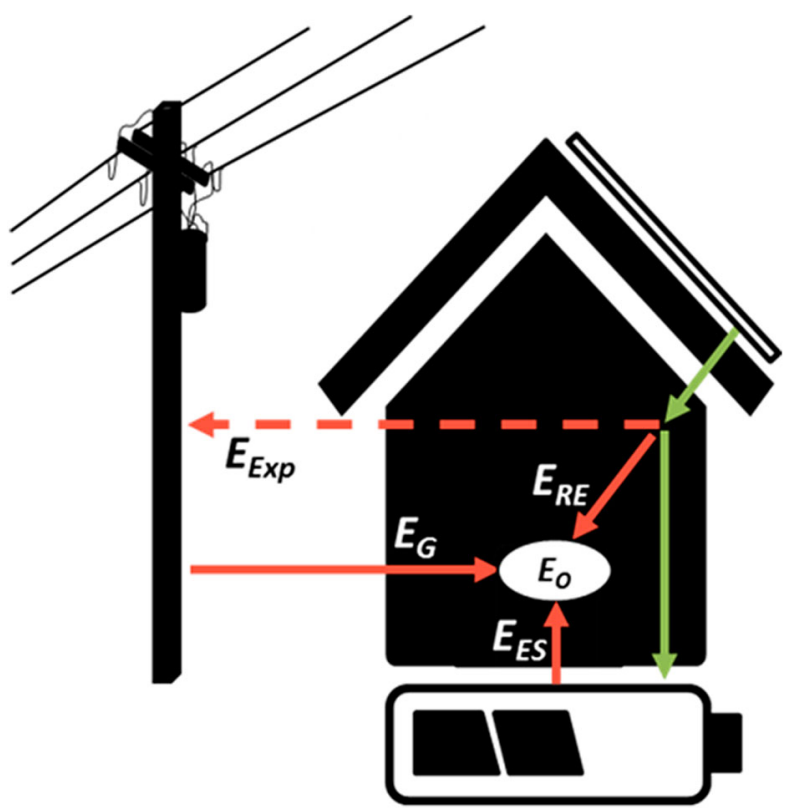

Figure 2. The possible energy fluxes occurring between the main components of the building energy system considered in this study.

its own embedded and operational impact. The analytical search for this cut-off value is the subject of this present study.

\subsection{GHG emissions balanced at the building level}

Now consider a building, a PV system, energy storage, and a connection with an electric grid. These elements and the different energy fluxes between them are presented in Figure 2. The possibility of exporting the surplus of on-site RE generated is shown by the horizontal red dashed line that vanishes when exports are not possible.

The GHG emissions of the operational phase of the building $\mathrm{GHG}_{0}$ are assessed on the basis of a cradle-to-grave LCA, following Equation (A1) presented in Appendix 1. When exporting electricity to the surrounding network is not possible, using Equation (A1) would mean that the building owner supports the burden of the energy used for his building alone, without those of the wasted electricity (e.g. the RE system belongs to a solar cooperative). More often, the building landlord owns the onsite RE system at the same time. In such a case, Equation (A1) is 
adapted (see Equation (A2) in Appendix 1) in order to account for the burden of all the electricity produced by $R E$, the part consumed directly or indirectly on-site, and the excess electricity that is lost. Within a balancing period of one year, all energy fluxes within the BES (Figure 2) and their associated GHG emissions are assessed at the hourly time-step; the energy fluxes important for solving Equations (A1) and (A2) are shown in red in Figure 2.

\section{Methodology}

\subsection{The global warming potential cut-off}

To determine the cut-off of energy storage GWP (GWP $\left.P_{E S, c}\right)$, we propose the following four-step methodology. In step (1), the final data regarding the energy consumption of the considered building, its RE production, and the grid's GWP need to be collected. These data should be evaluated at the hourly time-step over the course of one year. In step (2), the annual GHG emissions of the building's operational phase without ES are assessed. In step (3), we consider the implementation of ES of a given size. Then, we proceed to another assessment of the GHG emissions with the considered storage but with its GWPES set to zero. Finally, in step (4), the two assessments performed during steps (2) and (3) are compared. The GHG benefits obtained by ES implementation are divided by the amount of energy transmitted in the ES unit during the evaluation period. This is the cut-off value of energy storage GWP (GWP $P_{E S, c}$ ) that the energy storage unit should exhibit in order to have a balanced life-cycle impact on the GHG balance at the building level.

\subsection{Extension of the method to other indicators}

The same method explained in section 3.1 can easily be extended to other life-cycle indicators. In this study, we propose to treat the cumulative energy demand (CED) and its nonrenewable component $\left(\mathrm{CED}_{\mathrm{nr}}\right)$, as well as the cost, in a way similar to that used to explain GHG emissions.

When adapting the methodology explained in section 3.1 for the cost, the building owner's point of view is adopted. Assessing the life-cycle cost viability of an energy storage unit requires the collection of data regarding the electricity tariffs imposed by the local electricity provider and the price of on-site renewable systems.

\section{Testing the methodology}

\subsection{Modelling framework}

A versatile modelling framework previously developed (See Vuarnoz et al. 2018) is used to simulate the running conditions of the BES at the hourly time-step and to assess its annual performance according to Swiss standard SIA 2040 (2017). The choice of the hourly time-step allows us to take into account the dynamic interaction within the components of the building energy system.

Because the battery is stationary and, therefore, not subjected to temperature changes, modelling the degradation of the battery is assumed to be proportional to the amount of energy transmitted in storage. Energy storage is modelled using the following parameters: an initial storage capacity $C_{E S}$ in $\mathrm{kWh}$, a fading capacity factor $\mathrm{f}_{\mathrm{ES}}$ in $\%{ }^{*} \mathrm{kWh}^{-1}$, and round-trip efficiency $\eta$ in \% as in (Peterson, Apt, and Whitacre 2010).

\subsection{Energy-management procedure}

An energy-management procedure comprises a set of rules governing the energy fluxes between the components of the BES. As different optimizations can be prioritized, a number of different strategies are possible. In this study, as in most simple commercialized EMSs, the following general rules apply:

- For the supply of $E_{0}$, the merit-order of energy sources is: 1) from $R E ; 2$ ) from $E S ; 3)$ from the grid. If one source is unavailable or insufficient, then the next one is considered.

- For the management of on-site renewable-energy production, energy goes: (1) to supply $E_{0}$; if a surplus of RE occurs, energy goes to (2) ES. In the event that the ES unit is full, the remaining excess energy could either be exported to the surrounding electric grid (3) or discarded (4).

\subsection{Case study}

An appropriate case study comprises a building for which the energy demand, RE production, and carbon footprint of the electricity supply mix are all assessed on an hourly basis over the span of one year. For this reason, the project of the building for the smart living lab (Andersen and Rey 2019), with construction planned for 2022 in Fribourg, Switzerland, constitutes a perfect case study.

An architectural feasibility study considering an energy reference area of $4000 \mathrm{~m}^{2}$ serves as a basis for the assessment of the building's energy demands (additional details can be found at Vuarnoz et al. (2018)). The needs of the building's users are assimilated to an office building according to SIA 2024 (2015). A netzero energy building (NZEB) approach is adopted. The planned technical installations include solar thermal panels to meet $60 \%$ of the domestic hot-water energy demand. All other thermal needs are provided by a heat pump. Electricity is generated either by on-site PV panels or by the Swiss grid mix.

Cadmium telluride PV panels $(\eta=15.1 \%)$ are considered to partially cover the building, according to Table 1. Different PV orientations were selected not for optimal energy use but to evaluate the consequences of differing PV integration on the building's exterior surfaces. In order to assess the GWP of the electricity provided by PV (GWPPV), embedded emissions and energies have been applied from the work conducted by Frischknecht et al. (2015), and the amount of RE harvested by building-integrated photovoltaics (BIPV) has been evaluated with the help of crm solar software (smarsys, 2017) with hourly weather data files from Swiss weather station at Fribourg-Posieux. The lifespan of a photovoltaic system is assumed to be 30 years (Frischknecht et al. 2015) and to have a constant rate of efficiency over time. The energy and carbon footprints of the electricity generated by the PV panels considered in the case study are presented in Table 1 and are adopted from the work conducted by Vuarnoz et al. (2018).

The levelized cost of the renewable energy system is determined by the investment cost and the operational cost collected 
Table 1. Characteristics of the PV system.

\begin{tabular}{|c|c|c|c|c|c|c|}
\hline Orientation & Area $\left(\mathrm{m}^{2}\right)$ & $\mathrm{GWP}\left(\mathrm{kg} \mathrm{CO}_{2-\mathrm{eq}} / \mathrm{kWh}\right)$ & $\mathrm{CED}\left(\mathrm{MJ}_{\mathrm{eq}} / \mathrm{kWh}\right)$ & $\mathrm{CED}_{\mathrm{nr}}\left(\mathrm{MJ}_{\mathrm{eq}} / \mathrm{kWh}\right)$ & $\begin{array}{c}\text { CRE without subsidies }_{\text {(CHF/kWh) }} \\
\text { (CHF }\end{array}$ & $\begin{array}{c}\text { C } \mathrm{RE} \text { with subsidies } \\
(\mathrm{CHF} / \mathrm{kWh})\end{array}$ \\
\hline East $\left(75^{\circ}\right)$ & 343 & 0.094 & 1.52 & 1.41 & 0.324 & 0.312 \\
\hline West $\left(255^{\circ}\right)$ & 343 & 0.067 & 1.09 & 1.00 & 0.231 & 0.223 \\
\hline
\end{tabular}

Table 2. Partial cost of the grid mix (Groupe E 2019).

\begin{tabular}{llc}
\hline Period & & Tarif (CHF/kWh) \\
\hline Winter & High* & 0.172 \\
$(01 / 10-31 / 03)$ & Low $^{* *}$ & 0.111 \\
Summer & High* & 0.140 \\
$(01 / 04-30 / 09)$ & Low $^{* *}$ & 0.082 \\
\hline
\end{tabular}

*(mo-fri: 07:00-23:00; sat: 07:00-13:30).

**(other than*).

in the study by Moreno Aguacil (2019). These prices, derived specifically from the Swiss market, include all the necessary components of the renewable system (PV panels, junction box, connections, cabling and inverters). A recycling tax is also taken into consideration in the purchase of the system (SENS eRecycling 2019). The specific levelized cost $C_{R E}$ of electricity provided by the specific renewable system considered for our case study is presented in Table 1, both with and without possible governmental subsidies (Pronovo 2019).

The selection of various positions for the implementation of BIPV panels allows the optimization of RE harvesting time and, therefore, increases the building's potential energy autonomy. However, the footprints and levelized costs of PV are directly dependent on the capacity of PVs to harvest solar radiation. Only the addition of PV units to the roof allows the production of electricity at a cost below the feed-in tariff.

Due to the location of the case study, the Swiss grid is considered. Hourly GWP data for the grid have been evaluated on the basis of an attributional cradle-to-grave LCA by Vuarnoz and Jusselme (2018a). Based on this study, which considers a one-year period of 2015-2016, the values of $\mathrm{GWP}_{\mathrm{G}}$ range from $0.029-0.414 \mathrm{~kg} \mathrm{CO} \mathrm{CO}_{2-\text { eq }} / \mathrm{kWh}$, with a mean annual GWP of $0.203 \mathrm{~kg} \mathrm{CO}{ }_{2-\mathrm{eq}} / \mathrm{kWh}$ and a relative standard deviation of $41 \%$. The data for the hourly energy footprints of the Swiss grid used in this study are taken from Vuarnoz and Jusselme (2018a). The mean annual values for the Swiss mix are $11.86 \mathrm{MJ}_{\text {eq }} / \mathrm{kWh}$ for the CED and $10.46 \mathrm{MJ}_{\mathrm{eq}} / \mathrm{kWh}$ for $\mathrm{CED}_{\mathrm{nr}}$ with a relative standard deviation of 10.9 and $18.1 \%$, respectively.

In Fribourg, the cost of electricity is subject to four different electricity tariffs $C_{G}$ throughout the year (see Table 2 ). In addition, the final electricity bill includes a fixed yearly fee $(518.30$ $\mathrm{CHF} / \mathrm{yr}$ ) and a variable power fee (5.90 CHF/kW*mo). In Fribourg, $\mathrm{RE}$ can be sold at any time with a single feed-in-tariff of 0.093 $\mathrm{CHF} / \mathrm{kwh}$. It is assumed that the power grid system does not enter its end-of-life phase during the time frame of this analysis.

A lithium-ion electrochemical battery is considered in the study with a round-trip efficiency (0.9). The degradation of the battery is assumed by a capacity fading factor $\left(-6 \mathrm{E}-04 \% \mathrm{kWh}^{-1}\right)$ that has been evaluated on the basis of measurements performed by the product manufacturer (Vuarnoz et al. 2018). As the influence of the storage size is of prior importance, the simulations are conducted over a range of possible battery capacities.

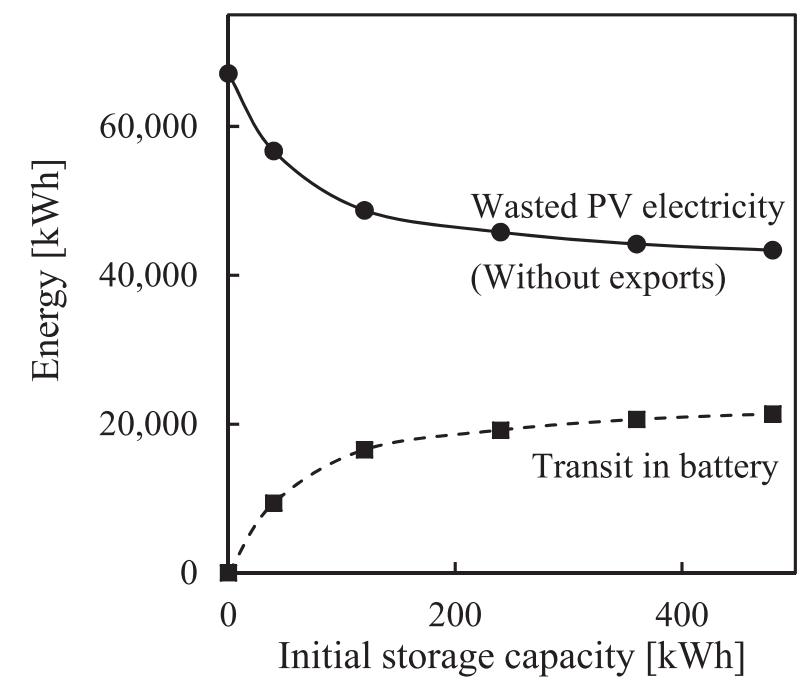

Figure 3. Amount of PV electricity that cannot be exported and amount of energy transited in the energy storage during a one-year period. Same results of transit are obtained with or without export to the grid of the surplus RE generation.

\section{Results}

First, we look at the annual amount of energy $\mathrm{E}_{\mathrm{T}}$ transmitted in storage. This amount is independent of the scheme of export management (see Figure 3) and evolves similarly to an $\mathrm{E}_{\mathrm{T}}=\mathrm{a}^{*}(1$ - $\left.\exp \left(-b C_{E S}\right)\right)$ function. This function, also known as an ease-out curve, is centred at the origin, with a horizontal asymptote when increasing $C_{E S}$. This feature is explained by the finite amount of solar irradiance independent of the size of the storage unit. The NZEB balance principle is responsible for a large amount of wasted electricity when it is not exportable.

\subsection{Greenhouse gas results}

The GHG results obtained when applying the methodology explained in Section 3.1 to the considered case study (section 4.3) and for two schemes of renewable excess power management are presented in Figure 4 as a function of the size of the storage capacity. When the export of excess PV electricity is not possible (or not allowed), when increasing from zero to the ES capacity, the GHG emissions appear to first decrease and then converge (see Figure 4). When implementing an ES system, the excess PV electricity that is not used immediately for the building can be stored for later use instead of being wasted. This reduces the amount of electricity imports and increases the share of RE in the building's energy consumption. As a result, compared to a system without $E S\left(C_{E S}=0\right)$, a reduction of GHG emissions is now obtained. The gap $\delta$, which is indicated in Figure 4, corresponds to the operational benefits of using ES. This gap corresponds to the maximum embodied carbon that ES should exhibit in order to lead to emission neutrality. In Figure 5, the 


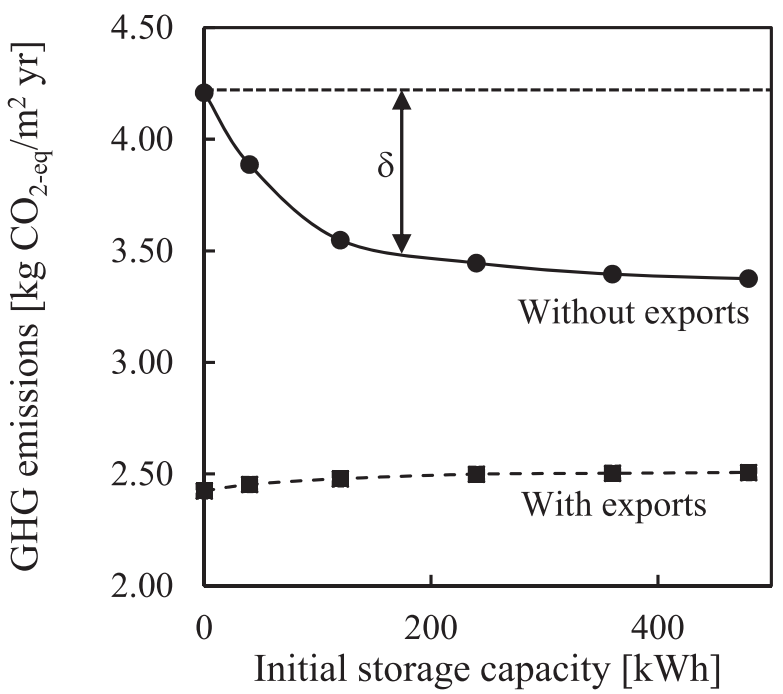

Figure 4. GHG emissions at the building's level.

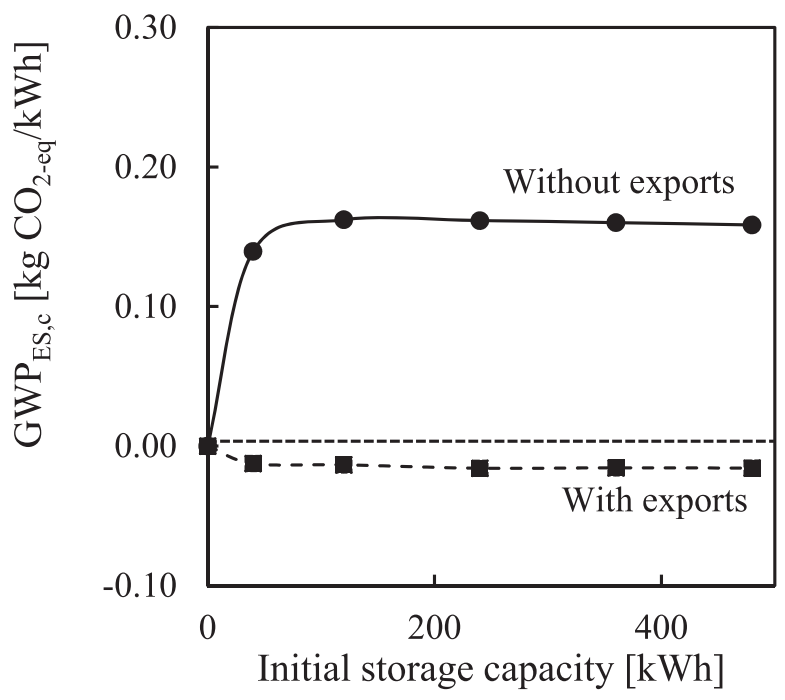

Figure 5. GWP $\mathrm{ES}, \mathrm{c}_{\mathrm{c}}$ to ensure $\mathrm{GHG}$ emission mitigation at the building level.

energy storage GWP cut-off $\left(G_{W P} P_{E S, c}\right)$ is presented as a function of ES capacity size and shows a converging value of 0.158 $\mathrm{kgCO}_{2-\text { eq }} / \mathrm{kWh}$.

In the case of possible exports of surplus PV electricity, a dir ect valuation of this RE excess is possible through the grid, even if ES is not part of the BES. The valuation of export to the grid is possible without extra embedded impacts and energy losses of local ES. Although the GHG emissions stagnate when increasing ES capacity size, higher GHG emissions are always obtained in comparison with the initial case without ES (Figure 4). Consequently, the proposed method explicated in section 3.1 provides negative values for $\mathrm{GWP}_{\mathrm{ES}, \mathrm{c}}$ that are mathematically correct but are, in reality, non-existent. This is further addressed in section 5.4 .

\subsection{Primary energy results}

For the same reasons as those related to the neutral GWP assessment, only the scheme that does not consider exports possible

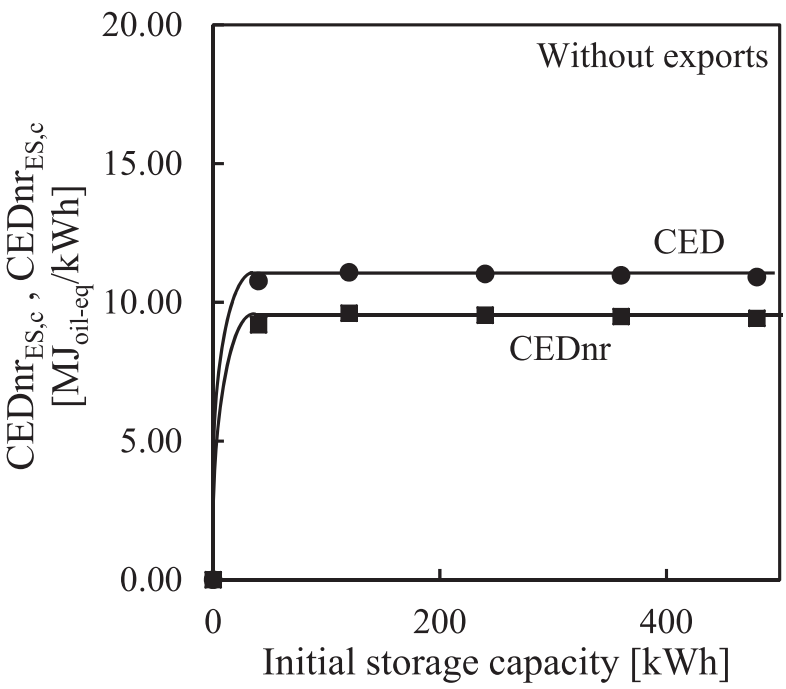

Figure 6. $C E D_{E S, C}$ and $C E D n r_{E S, C}$ to ensure a mitigation of respectively the primary energy and its non-renewable part at the building level when implementing an energy storage.

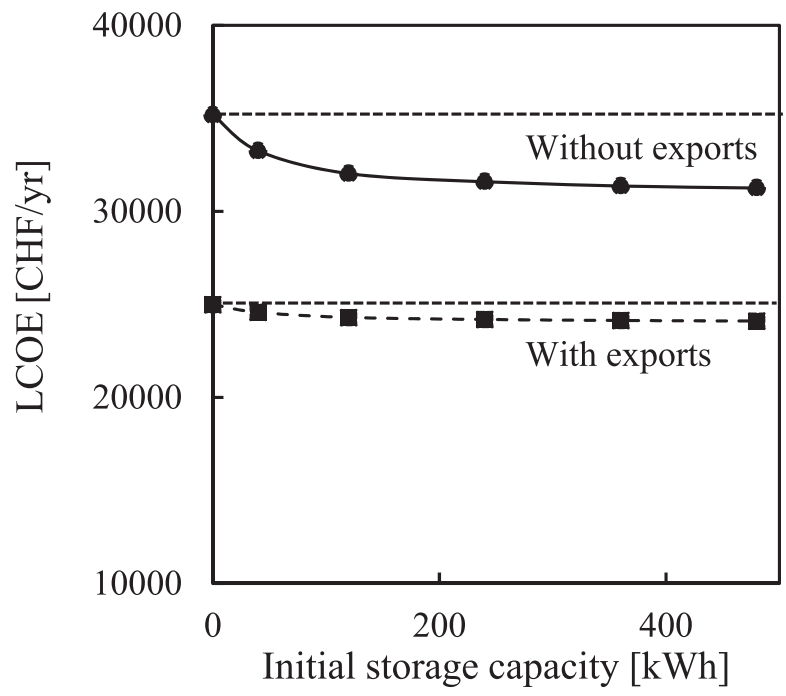

Figure 7. Annual LCOE of the building operational phase in function of an evolving energy storage capacity

is presented in Figure 6. The obtained tendencies of both functions $C_{E D} D_{E S, C}=f\left(C_{E S}\right)$ and $C E D n r_{E S, C}=f\left(C_{E S}\right)$ are similar to the one obtained for the GWP (see Figure 5).

The convergence value for the primary energy cut-off $\left(C E D_{E S, C}\right)$ is 10.9 and $9.4 \mathrm{MJ}_{\text {eq }} / \mathrm{kWh}$ for its non-renewable portion.

\subsection{Cost results}

The results obtained include the evolution of the annual levelized cost of energy (LCOE) of the building operational phase with various storage capacity and are presented in Figure 7.

Thanks to the financial gain obtained by selling excess electricity, without energy storage, the annual LCOE is substantially lower when the exportation of renewable energy is possible.

In contrast to the results obtained in the assessment of the GHG emissions and primary energy, integrating an energy 


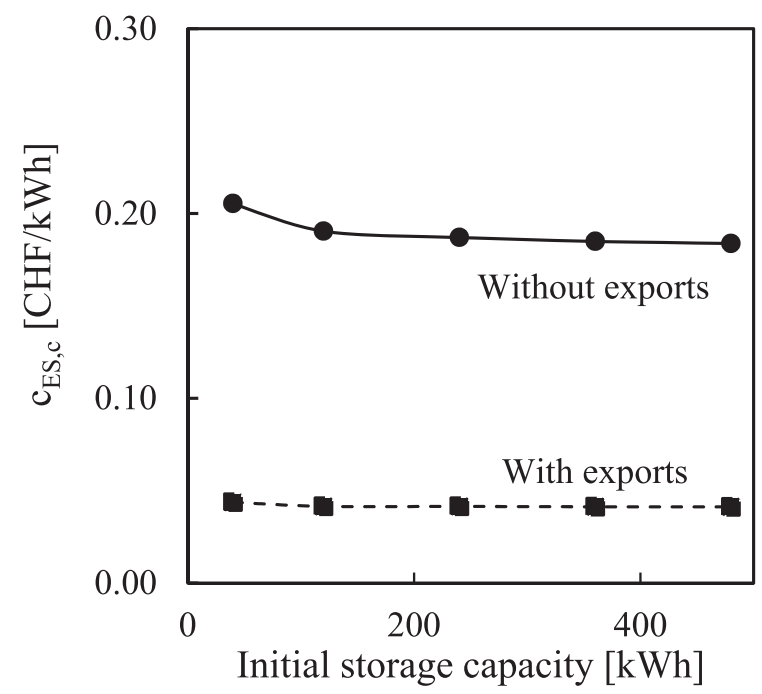

Figure 8. $C_{E S, c}$ to ensure a cost mitigation of the LCOEs when implementing an energy storage of various capacity

storage unit when there is, at the same time, the possibility of exporting electricity, may also induce financial benefits.

By increasing the installed energy storage capacity, the potential to reduce the LCOE is more pronounced when export is not possible. From these obtainable benefits, we can then assess the cut-off results in the levelized cost of energy storage in the same way as done previously for GHG and primary energy. The results are presented in Figure 8 and show converging values $\mathrm{C}_{\mathrm{ES}, \mathrm{C}}$ of 0.058 and $0.184 \mathrm{CHF} / \mathrm{kWh}$, respectively, with and without possible energy exports.

\subsection{Contextualization}

Nowadays, the Li-lon technology is the most accessible and most used technology in terms of commercial batteries (REF). The study uses an inventory analysis performed using the ecoinvent database (Frischknecht et al. 2005) and realistic parameters (the deterioration measurements performed by the manufacturer for a constant depth of discharge (DOD) of $80 \%$ (Vuarnoz et al. 2018), a round-trip efficiency of 0.9 , and the same end-of-life of a battery, i.e. when the value of $80 \%$ of the initial storage capacity is reached), the primary energies (CED and CEDnr) and GHG emissions of commercial lithium-ion batteries have been assessed. The difference between our model and the standardized test conducted by the manufacturer lies in the constant evolution of the battery's DOD during the transient operation of the BES. The results are presented in Table 3, and are far below the cut-off values assessed specifically for our case study. The extra margin is larger for energy than for carbon footprint and proves the possible GHG and primary energy mitigation at the building level only when surplus PV electricity cannot be exported to the surrounding grid.

Concerning the costs, and according to the Swiss Competence Centre for Energy Research (SCCER HaE-Storage 2017), the price of Li-ion batteries in 2016 was $310 \mathrm{CHF} / \mathrm{MWh}$, so today, the cut-off for the cost of batteries is lower than the market price (See Table 3). The operational profitability is not enough to pay-back the battery investment for any of the export scheme. Evolving
Table 3. Energy and carbon footprints of commercialized Li-ion battery found in the literature. (Without electricity exports).

\begin{tabular}{lccc}
\hline Battery Technology & $\begin{array}{c}\text { GWP } \\
\text { (kgCO2-eq/kWh) }\end{array}$ & $\begin{array}{c}\text { CED } \\
\text { (MJeq/kWh) }\end{array}$ & $\begin{array}{c}\text { CEDnr } \\
\text { (MJeq/kWh) }\end{array}$ \\
\hline $\begin{array}{c}\text { Li-lon Graphite-based } \\
\text { (Vuarnoz et al. 2018) }\end{array}$ & 0.021 & 0.351 & 0.319 \\
$\begin{array}{c}\text { Li-lon Titanate-based } \\
\text { (Vuarnoz et al. 2018) }\end{array}$ & 0.007 & 0.117 & 0.106 \\
\begin{tabular}{l} 
Cut-off values \\
\hline
\end{tabular} & 0.158 & 10.913 & 9.428 \\
\hline
\end{tabular}

Table 4. Mitigation tendencies according the scheme of export.

\begin{tabular}{llll}
\hline $\begin{array}{l}\text { Possibility to mitigate the } \\
\text { concerned indicator }\end{array}$ & \multicolumn{1}{c}{ GHG } & CED; CEDnr & LCOE \\
\hline $\begin{array}{l}\text { With possible exports } \\
\text { Without exports }\end{array}$ & $\begin{array}{l}\text { not achievable } \\
\text { possible }\end{array}$ & $\begin{array}{l}\text { not achievable } \\
\text { possible }\end{array}$ & $\begin{array}{l}\text { possible } \\
\text { possible }\end{array}$ \\
\hline
\end{tabular}

market prices show a repeated reduction in battery costs (with an annual average close to $22 \%$ for the period 2010-2018 (Logan 2019)) and will, therefore, soon offer products that offer financial benefits.

Although the proposed methodology does not directly aim to define an optimal sizing for storage capacity, its purpose is to certify the life-cycle viability of a given energy storage design according to pre-selected life-cycle indicators. To illustrate possible battery sizes within the frame of the case study when considering lithium-ion technology, a full day of autonomy during mid-season (spring and autumn) corresponds to $350 \mathrm{kWh}$ (3070 kg with an energy density of $114 \mathrm{Wh} / \mathrm{kg}$ ). During the same period of the year, storing the daily excess PV production would require a storage capacity of $120 \mathrm{kWh}$ (which represents 1050 $\mathrm{kg}$ ). these two possible capacity sizes (350 and $120 \mathrm{kWh}$ ) and their associated embedded $\mathrm{CO}_{2-\text { eq }}$ correspond, respectively, to approximately $30 \%$ and $10 \%$ of the GHG emission targets proposed by the Swiss standard SIA 2040 (2017) for the construction and exploitation of a new building.

Beyond the specifics of our case study, the phenomenology of the different limits of viability (i.e. the cut-off results) unveils the importance of the scheme of exports in the possibility to mitigate a given life-cycle indicator (See Table 4).

As the characteristics of electricity provided by both the grid and RE directly influence the level in the convergence of the cut-off values, the geographic context is of major importance in the viability of ES in buildings. Let's consider the same case study with the same energy demand but with the grid electricity supplied by a national grid other than the Swiss mix. According to Vuarnoz and Jusselme (2018a), the mean annual carbon footprint of the French and German grid assessed on the basis of hourly time-steps exhibit a carbon footprint of 0.080 and $0.860 \mathrm{kgCO}_{2-\mathrm{eq}} / \mathrm{kWh}$, respectively. Looking back at Figure 1, it is clear that a carbon-intensive grid mix would generate a larger GWP threshold for storage. This is the case when we apply our case study to the context of Germany, with a resulting GWP $P_{E S, c}$ of $0.828 \mathrm{kgCO}_{2-\text { eq }} / \mathrm{kWh}$. In contrast, the very low carbon footprint of French electricity allows a value of only $\mathrm{GWP}_{\mathrm{ES}, \mathrm{c}}=0.044$ $\mathrm{kgCO}_{2-\mathrm{eq}} / \mathrm{kWh}$, which is, at the current time, very challenging with respect to commercialized energy storage.

Obtained results have a direct impact on the design of the external surface of active buildings since the life-cycle footprints of intermittent RE harvester technologies are in direct relation 
with their orientation and abilities to capture energy (See e.g. Table 1). To satisfy the viability of energy storage in buildings, the RE footprints must be as low as possible, but at least inferior to the grid footprint minus the one of the energy storage (See Figure 1).

The limitations of the study and the robustness of the results are similar to those usually encountered by engineers and LCA practitioners when they deal with environmental impacts of buildings. In particular, if LCA studies are known to be appropriate for performing comparative studies, they have, at the same time, significant drawbacks in regard to generating robust absolute values. This is particularly true when dealing with construction materials and energy medium uncertainties (Reap et al. 2008; Hoxha et al. 2017). Nevertheless, 'estimation for life cycle environmental emissions cannot be avoided because of the uncertainty involved' (Weber et al. 2010).

\section{Conclusion}

This study aims to investigate the life-cycle impacts of an energy storage system when embedded in buildings. A general methodology for assessing the cut-off value between extra embedded impacts and operational gains related to energy storage is proposed. This is particularly relevant for ensuring the lifecycle viability of energy storage with a pre-selected technology and capacity and is designed to ensure the essential prerequisites for energy storage at the building level. Although any kind of environmental indicators used in LCA can be assessed, this new methodology is explained for GHG emissions mitigation and then derived for the primary energy and the cost indicators.

The methodology has been tested in a case study consisting of a feasibility project of a high-performance building located in Switzerland. The numerical results unveil the prior importance of the scheme for the surplus RE management and the different mechanisms in the evolution of the cut-off values when varying the storage capacity. Mitigation of the primary energy and the GHG emissions is achievable by implementing ES only without electricity exports to the grid. In such a case, the limits of viability for both indicators are easily satisfied with commercial Li-lon products. A reduction of operating costs is possible whatever the export scheme, but not enough to recover the integral lifecycle cost of batteries. The economic viability of implementing energy storage in buildings is compromised today, but the continuing reduction of battery costs will soon allow for overcoming the challenge of the economic viability of energy storage in buildings.

Beyond the specific results achieved for the presented case study, we found the life-cycle characteristics of the energy sources powering the building, and therefore how and in which environment the building is designed, to be a major influence on the level of the viability cut-off values of energy storage. If it is very easy to mitigate GHG emissions in buildings by using electrochemical energy storage in Germany, this might be highly challenging, technologically, with low-carbon electricity such as that delivered by the French grid. Although building engineers and architects cannot influence the quality of the surrounding electrical grid, their competence and abilities enable the implementation of renewable energy harvesting, which minimizes the life-cycle footprint of the electricity produced, e.g. by a strategic orientation of solar panels that maximize the amount of onsite renewable energy production.

\section{Acknowledgements}

The work presented in this paper has been funded by the State of Fribourg and the EPFL and the HES-SO. The author would like to thanks Philippe Couty for valuable discussions on the subject of electricity storage and LCA.

\section{Disclosure statement}

No potential conflict of interest was reported by the author(s).

\section{Funding}

This work was supported by State of Fribourg [message du Conseil d'Etat au Grand Conseil 2014-DEE-22].

\section{References}

Andersen, M., and E. Rey (ed.). 2019. Exploring - Research Driven Building Design. Zurich, Switzerland: Park Book. 279p.

Barnhart, C. J., and S. M. Benson. 2013. "On the Importance of Reducing the Energetic and Material Demands of Electrical Energy Storage." Energy \& Environmental Science 6 (4): 1083-1092.

Celik, A. N., T. Muneer, and P. Clarke. 2007. "Optimal Sizing and Life Cycle Assessment of Residential Photovoltaic Energy Systems with Battery Storage." Progress in Photovoltaics: Research and Applications 16 (1): 69-85.

Doroudchi, E., S. K. Pal, M. Lehtonen, and J. Kyyrä. 2015. "Optimizing Energy Cost via Battery Sizing in Residential PV/Battery Systems." In 2015 IEEE Innovative Smart Grid Technologies-Asia (ISGT ASIA), Bangkok, Thailand.

Favre, L., T. M. Schafer, J. L. Robyr, and E. L. Niederhäuser. 2018. "Intelligent Algorithm for Energy, both Thermal and Electrical, Economic and Ecological Optimization for a Smart Building." In 2018 IEEE International Energy Conference (ENERGYCON), Limassol, Cyprus.

Frischknecht, R., R. Itten, P. Sinha, M. de Wild-Scholten, J. Zhang, G. A. Heath, and C. Olson. 2015. Life cycle inventories and life cycle assessment of photovoltaic systems. International Energy Agency (IEA) Report IEA-PVPS 12-04:2015.

Frischknecht, Rolf, Niels Jungbluth, Hans-Jörg Althaus, Gabor Doka, Roberto Dones, Thomas Heck, Stefanie Hellweg, et al. 2005. "The Ecoinvent Database: Overview and Methodological Framework (7 pp)." The International Journal of Life Cycle Assessment 10 (1): 3-9.

Groupe E. 2019. Fiche tarifaire 2019, 28p

Guarino, Francesco, Pietro Cassarà, Sonia Longo, Maurizio Cellura, and Erina Ferro. 2015. "Load Match Optimisation of a Residential Building Case Study: A Cross-Entropy Based Electricity Storage Sizing Algorithm." Applied Energy 154: 380-391.

Hoan-Anh, D., B. Delinchant, and F. Wurtz. 2013. Toward Autonomous Photovoltaic Building Energy Management: Modeling and Control of Electro Chemical Batteries. Proc. of 13th Conf. of IBPSA, Chamberry, France

Hoxha, Endrit, Guillaume Habert, Sébastien Lasvaux, Jacques Chevalier, and Robert Le Roy. 2017. "Influence of Construction Material Uncertainties on Residential Building LCA Reliability." Journal of Cleaner Production 144: 33-47.

Huang, T., and D. Liu. 2011. "Residential Energy System Control and Management using Adaptive Dynamic Programming." In The 2011 International.Joint Conference on Neural Networks (IJCNN 2011). San Jose, USA.

Kopsakangas-Savolainen, M., M. K. Mattinen, K. Manninen, and A. Nissinen. 2017. "Hourly-Based Greenhouse Gas Emissions of Electricity-Cases Demonstrating Possibilities for Households and Companies to Decrease their Emissions." Journal of Cleaner Production 153: 384-396.

Kourkoumpas, Dimitrios-Sotirios, Georgios Benekos, Nikolaos Nikolopoulos, Sotirios Karellas, Panagiotis Grammelis, and Emmanouel Kakaras. 2018. "A Review of key Environmental and Energy Performance Indicators for the Case of Renewable Energy Systems When Integrated with Storage Solutions." Applied Energy 231: 380-398. 
Litjens, G. B. M. A., E. Worrell, and W. G. J. H. M. van Sark. 2018. "Lowering Greenhouse gas Emissions in the Built Environment by Combining Ground Source Heat Pumps, Photovoltaics and Battery Storage." Energy and Buildings 180: 51-71.

Logan, G.-S. 2019. A Behind the Scenes Take on Lithium-ion Battery Prices. Bloomberg, NEF. Accessed December 19 2019. https://about.bnef.com/ blog/behind-scenes-take-lithium-ion-battery-prices/.

McManus, M. C. 2015. "Environmental Consequences of the use of Batteries in low Carbon Systems: The Impact of Battery Production." Applied Energy 93: 288-295.

Milovanoff, A. 2016. "Optimisation environnementale de la gestion des consommations électriques en temps réel." Diss. Ecole Polytechnique, Montréal, Canada.

Moreno Aguacil, S. 2019. Architectural Design Strategies for BuildingIntegrated Photovoltaics (BIPV) in Residential Building Renovation, PhD dissertation $\mathrm{n}^{\circ} 9332$, EPFL.

Peterson, Scott B., Jay Apt, and J. F. Whitacre. 2010. "Lithium-ion Battery Cell Degradation Resulting From Realistic Vehicle and Vehicle-to-Grid Utilization." Journal of Power Sources 195 (8): 2385-2392.

Pronovo. 2019. "Programme d'encouragement, Rétribution unique." Acces sed December 19 2019. https://pronovo.ch/fr/financement/systeme-deretribution-de-linjection-sri/.

Reap, John, Felipe Roman, Scott Duncan, and Bert Bras. 2008. "A Survey of Unresolved Problems in Life Cycle Assessment." The International Journal of Life Cycle Assessment 13 (5): 374-388.

Roux, Charlotte, Patrick Schalbart, and Bruno Peuportier. 2016. "Accounting for Temporal Variation of Electricity Production and Consumption in the LCA of an Energy-Efficient House." Journal of Cleaner Production 113: 532-540.

SENS e-Recycling. 2019. "Liste des équipements et des tarifs." Accessed December 19 2019. https://www.erecycling.ch/.

SIA 2024. 2015. Données d'utilisation des locaux pour l'énergie et les installations du bâtiment, 1-152.

SIA 2040. 2017. Efficiency path for energy, 1-27.

Smarsys. 2017. "Gestion de parc photovoltaïque." Accessed December 19 2019. http://www.smarsys.com/services/gestion-de-parc-photovoltaique

Spork, Charlie C., Abel Chavez, Xavier Gabarrell Durany, Martin K. Patel, and Gara Villalba Méndez. 2015. "Increasing Precision in Greenhouse Gas Accounting Using Real-Time Emission Factors." Journal of Industrial Ecology 19 (3): 380-390.

Swiss Competence Center for Energy Reserch- Heat and Electricity Storage. 2017. SCCER HaE-Storage - Annual Activity Report 2016. 84p.

Tomorrow. 2018. "Electricity Map Live." Accessed April 16 2018. http://www. smarsys.com/services/gestion-de-parc-photovoltaique/.

Velik, R. 2013. "The Influence of Battery Storage Size on Photovoltaics Energy Self-Consumption for Grid-Connected Residential Buildings." International Journal of Advanced Renewable Energy Research 2 (6): 1-7. http://neredataltics.org/journals/index.php/IJARER/article/view/391.

Vieira, Filomeno M., Pedro S. Moura, and Aníbal T. de Almeida. 2017. “Energy Storage System for Self-Consumption of Photovoltaic Energy in Residential Zero Energy Buildings." Renewable Energy 103: 308-320.
Vuarnoz, D., S. Cozza, T. Jusselme, G. Magnin, T. Schafer, P. Couty, and E.L. Niederhauser. 2018. "Integrating Hourly Life-Cycle Energy and Carbon Emissions of Energy Supply in Buildings." Sustainable Cities and Society 43: 305-316.

Vuarnoz, D., and T. Jusselme. 2018a. "Temporal Variation in the Energy use and Greenhouse gas Emissions of the Electricity Provided by the Swiss Grid." Energy 161: 573-582.

Vuarnoz, D., and T. Jusselme. 2018b. "Neutral Global Warming Potential Target of Electricity Storage as Threshold for Greenhouse Gas Emission Mitigation in Buildings." PLEA 2018 Hong-Kong - 38th Int. Conf. on Passive and Low Energy Architecture.

Vuarnoz, D., T. Jusselme, S. Cozza, E. Rey, and M. Andersen. 2016. "Studying the Dynamic Relationship between Energy Supply Carbon Content and Building Energy Demand." PLEA 2016 Los Angeles - 36th Int. Conf. on Passive and Low Energy Architecture.

Weber, Christopher L., Paulina Jaramillo, Joe Marriott, and Constantine Samaras. 2010. "Life Cycle Assessment and Grid Electricity: What do we Know and What can we Know?" Environmental Science \&amp; Technology 44: 1895-1901.

Wu, Xiaohua, Xiaosong $\mathrm{Hu}$, Xiaofeng Yin, Caiping Zhang, and Shide Qian. 2017. "Optimal Battery Sizing of Smart Home via Convex Programming." Energy 140: 444-453.

Zhang, Yang, Anders Lundblad, Pietro Elia Campana, F. Benavente, and Jinyue Yan. 2017. "Battery Sizing and Rule-Based Operation of GridConnected Photovoltaic-Battery System: A Case Study in Sweden." Energy Conversion and Management 133: 249-263.

\section{Appendix 1: GHG emissions balance at the building level}

The first case describes the situation where the building owner supports the burden of the energy used for his building alone, without those of the wasted electricity (e.g. the RE system belongs to a solar cooperative).

$$
\begin{aligned}
G H G_{O}= & \left(E_{R E} \times G W P_{R E}\right)+\left(E_{G} \times G W P_{G}\right)+\left(E_{E S} \times\left(G W P_{R E}+G W P_{E S}\right)\right) \\
& -E_{E X P} \times\left(G W P_{G}-G W P_{R E}\right)
\end{aligned}
$$

where $E$ denotes the energy flux and GWP the global warming potential. Indices $\mathrm{O}, \mathrm{RE}, \mathrm{G}$ and $\mathrm{ES}$ stand respectively for operative, renewable energy, grid and energy storage fluxes supplying the building's final electricity consumption.

Another case is when the building landlord owns the on-site RE system at the same time. In such a case, equation (A1) is adopted to account for the burden of all the electricity produced by RE, the amount consumed directly or indirectly on-site and the excess electricity that is lost.

$$
\begin{aligned}
G H G_{O}= & \left(E_{R E} \times G W P_{R E}\right)+\left(E_{G} \times G W P_{G}\right)+\left(E_{E S} \times\left(G W P_{R E}+G W P_{E S}\right)\right) \\
& +\left(E_{E X P} \times G W P_{R E}\right)
\end{aligned}
$$

